\title{
Independent Emergence of Resistance to Seven Chemical Classes of Fungicides in Botrytis cinerea
}

\author{
Dolores Fernández-Ortuño, Anja Grabke, Xingpeng Li, and Guido Schnabel
}

First, second, third, and fourth authors: School of Agricultural, Forest, \& Environmental Sciences, Clemson University, Clemson, SC 29634; and first author: Instituto de Hortofruticultura Subtropical y Mediterránea "La Mayora"-Universidad de Málaga-Consejo Superior de Investigaciones Científicas (IHSM-UMA-CSIC), Dept. de Microbiología, Campus de Teatinos, 29071 Málaga, Spain.

Accepted for publication 8 October 2014.

\begin{abstract}
Fernández-Ortuño, D., Grabke, A., Li, X., and Schnabel, G. 2015. Independent emergence of resistance to seven chemical classes of fungicides in Botrytis cinerea. Phytopathology 105:424-432.

Gray mold, caused by the fungal pathogen Botrytis cinerea, is one of the most destructive diseases of small fruit crops and control is largely dependent on the application of fungicides. As part of a region-wide resistance-monitoring program that investigated $1,890 \mathrm{~B}$. cinerea isolates from 189 fields in 10 states of the United States, we identified seven isolates $(0.4 \%)$ from five locations in four different states with unprecedented resistance to all seven Fungicide Resistance Action Committee (FRAC) codes with single-site modes of action including FRAC 1, 2, 7, 9, 11,12 , and 17 registered in the United States for gray mold control. Resistance to thiophanate-methyl, iprodione, boscalid, pyraclostrobin, and fenhexamid was based on target gene mutations that conferred E198A and F200Y in $\beta$-tubulin, I365N/S in Bos1, H272R/Y in SdhB,

G143A in Cytb, and T63I and F412S in Erg27. Isolates were grouped into MDR1 and MDR1h phenotypes based on sensitivity to fludioxonil and variations in transcription factor $m r r l$. MDR $1 \mathrm{~h}$ isolates had a previously described 3-bp deletion at position 497 in $m r r l$. Expression of $\mathrm{ABC}$ transporter atrB was increased in MDR1 isolates but highest in MDR1h isolates. None of the isolates with seven single resistances (SR) had identical nucleotide variations in target genes, indicating that they emerged independently. Multifungicide resistance phenotypes did not exhibit significant fitness penalties for the parameters used in this study, but MDR1h isolates produced more sclerotia at low temperatures and exhibited increased sensitivity to salt stress. In this study we show that current resistance management strategies have not been able to prevent the geographically independent development of resistance to all seven site-specific fungicides currently registered for gray mold control in the United States and document the presence of MDR1h in North America.
\end{abstract}

Botrytis cinerea Pers.:Fr., the causal agent of gray mold disease of strawberries (Fragaria $\times$ ananassa), is considered a high risk pathogen in regard to fungicide resistance development according to the Fungicide Resistance Action Committee (FRAC; www.frac.info). Its ability to adapt to fungicides quickly is based on multiple characteristics. $B$. cinerea can infect and produce secondary inoculum in the form of abundant sporulation on more than 230 known hosts. It is known for its polycyclic nature (46) and its ability to produce high genetic diversity within a population. Reasons may include sexual reproduction resulting in a very large number of ascospore lineages that are highly mobile and widespread $(4,10)$, the differences in gene content and gene variability as consequence of the multinucleate nature of both hyphal cells and conidia (42), the presence of extrachromosomal genetic elements including the chromosomes of the mitochondria, plasmids, the occurrence of mycoviruses, and the presence of transposable elements that influence genetic changes, especially expression of genes and gene mutations (40).

Several fungicides from different chemical classes are currently available for gray mold management, including the multisite fungicides captan and thiram (FRAC codes M3 and M4, respectively), and site-specific fungicides belonging to FRAC codes 1, 2, 7, 9, 11 (suppressive action only), 12, and 17. They are methyl benzimidazole carbamates (MBCs), dicarboximides (DCs), succinate dehydrogenase inhibitors (SDHIs), anilinopyrimidines (APs), quinone outside inhibitors (QoIs), phenylpyrroles (PPs), and sterol

Corresponding author: G. Schnabel; E-mail address: schnabe@clemson.edu biosynthesis inhibitors (SBIs) class III fungicides, respectively. Site-specific fungicides are vulnerable to resistance development and strategies have been developed to slow the emergence and selection of resistance under field conditions. The most common disease management practice consists of the alternation or tank mixtures of fungicides with different modes of action. For plasticulture-based production of strawberries in the southeastern United States, a multisite fungicide is typically applied every week throughout the season, whereas single-site fungicides are applied during the main peak bloom period, which vary depending on the cultivar (33). While FRAC code 2 fungicides, such as iprodione, are restricted to one application per season prior to bloom, many other FRAC codes have fewer restrictions and often may be applied legally up to five times per season.

Multifungicide resistance is commonly found in $B$. cinerea field isolates from commercial strawberry farms. Some studies have identified populations with a majority of isolates resistant to three or four FRAC groups. In a study carried out in German strawberry fields, fungicide resistance was commonly observed with many isolates possessing resistance to five FRAC codes, including 1, 2, 9, 11, and 17 (23). The most frequent multifungicide resistant phenotypes in Florida production fields were isolates resistant to FRAC codes 7, 9, and 11 and codes 7, 11, and 17 (1). Follow up studies established that these isolates were, without exception, also resistant to FRAC code 1 (A. Amiri, unpublished data). A survey of isolates from strawberry fields in Arkansas, Florida, Georgia, Maryland, North Carolina, South Carolina, and Virginia showed that the most common resistance phenotypes in 2013 were resistant to 1,2 , and 3 chemical classes of fungicides including FRAC codes 1, 11, and 7; codes 1, 11, and 9; and codes 1, 11, and 17 (13). In a recent study from commercial strawberry fields in South and 
North Carolina, the majority of $B$. cinerea isolates collected were resistant to four FRAC codes, including 1, 7, 9, and 11 (26).

As part of a resistance-monitoring program conducted during 2012 and 2013, a total of 1,890 B. cinerea isolates were collected from 10 states of the eastern United States. The isolates were analyzed for fungicide resistance to FRAC codes 1, 2, 7, 9, 11, 12, and 17 using a mycelial growth assay (13). Among the isolates tested we recovered seven (two from Connecticut, one from Georgia, three from South Carolina, and one from Virginia) that were resistant to all seven FRAC codes. The objectives of this study were to investigate the phenotypes, fitness, and the molecular mechanisms of resistance in these isolates.

\section{MATERIALS AND METHODS}

$B$. cinerea isolates used in this project. $B$. cinerea isolates were obtained from Connecticut, North Carolina, South Carolina, and Virginia strawberry fields, a Georgia blackberry field, and from a collaborator in Germany (Table 1). Single-spore isolation was performed as previously described (11). For conidia production, all isolates were grown on potato dextrose agar medium (PDA; Difco Laboratories, Sparks, MD) in 9-cm-diameter petri dishes for 10 days at $22^{\circ} \mathrm{C}$ with $14 \mathrm{~h}$ intervals of fluorescent light and darkness. B. cinerea isolate Do9_K_A31, a multidrug resistance type $1 \mathrm{~h}$ (MDR1h), originating from a strawberry field in Germany, was provided by M. Hahn (University of Kaiserslautern, Germany).

In vitro fungicide sensitivity. The following active ingredients were obtained as formulated products: thiophanate-methyl (Topsin M 70WP, Ceraxagri, King of Prussia, PA); iprodione (Rovral 4 Flowable, Bayer CropScience, Research Triangle Park, NC); boscalid (Endura fungicide 70\%, wt/wt, BASF); cyprodinil (Vangard WG fungicide, Syngenta Crop Protection, Greensboro, NC); pyraclostrobin (Cabrio EG fungicide 20\%, wt/wt, BASF Corporation, Research Triangle Park, NC); fludioxonil (Scholar SC fungicide, Syngenta); and fenhexamid (Elevate $50 \mathrm{WDG}$, Arysta Life Science, Cary, NC) representing FRAC codes 1, 2, 7, 9, 11, 12, and 17 , respectively. Fenhexamid, fludioxonil, iprodione, and thiophanate-methyl were tested in $1 \%$ malt extract agar (MEA) (44). Pyraclostrobin plus the alternative oxidase inhibitor salicyl hydroxamic acid (SHAM) at $100 \mu \mathrm{g} / \mathrm{ml}$ was added to $1 \%$ MEA (44). Cyprodinil was tested in $0.5 \%$ sucrose agar (SA). Boscalid was tested in $0.5 \%$ yeast extract agar (YEA) to avoid the interference of sugars with the assay (43). The unique multifungicide resistance phenotype of the isolates from the United States was initially discovered using a mycelial growth assay (13) and then further characterized in this study with a spore germination assay (44) to determine resistance categories, including low resistant (LR), moderately resistant (MR), resistant (R), and highly resistant (HR).

MDR phenotypes were identified by spore germination assay as previously described (23). All MDR isolates were able to germinate at $5 \mu \mathrm{g} / \mathrm{ml}$ tolnaftate. MDR1 and MDR1h isolates were able to fully germinate at $0.03 \mu \mathrm{g} / \mathrm{ml}$ cyprodinil and $0.2 \mu \mathrm{g} / \mathrm{ml}$ fludioxonil; however, only MDR1h isolates were able to germinate at $1 \mu \mathrm{g} / \mathrm{ml}$ fludioxonil. In contrast, MDR2 and MDR3 isolates are able to grow at $0.6 \mu \mathrm{g} / \mathrm{ml}$ fenhexamid and $50 \mu \mathrm{g} / \mathrm{ml}$ cycloheximide (23). Cyprodinil, fludioxonil, and tolnaftate were tested on $0.5 \%$ SA medium and fenhexamid and cycloheximide were tested in yeast bacto acetate agar (YBA) medium (23). Germination was assessed visually under a microscope (OLYMPUS BX41TF, Olympus Optical Co. Ltd., Japan) at $40 \times$ magnification after $16 \mathrm{~h}$ of incubation at $22^{\circ} \mathrm{C}$.

The effective inhibitory drug concentration at which $50 \%$ inhibition occurs $\left(\mathrm{EC}_{50} ; \mu \mathrm{g} / \mathrm{ml}\right)$ for fludioxonil was determined as described previously (19) with minor modifications. Briefly, 1,000 spores were transferred to $0.1-\mathrm{ml}$ 96-microplate cultures. Tests were performed in malt extract broth with final concentrations of 0.01 , $0.04,0.12,0.37,1.1,3.3$, and $10 \mu \mathrm{g} / \mathrm{ml}$ of fludioxonil. After $48 \mathrm{~h}$ of incubation in the dark at $22^{\circ} \mathrm{C}$, light absorption at $\mathrm{A}_{600 \mathrm{~nm}}$ was determined. The experiment was repeated.
DNA extraction, amplification and sequencing of $\boldsymbol{\beta}$ tubulin, cytb, bos1, erg27, sdhB, and mrrl genes, and the $\boldsymbol{m} \boldsymbol{f} \boldsymbol{M} \mathbf{2}$ promoter regions. DNA from isolates FLOR5, HP9, NC4, HRY1, JEY2013.1, JEY2013.2, JLEY2, CT1, CT3, and UGA1 was extracted as described previously (9). The partial $\beta$-tubulin and cytochrome $b(c y t b)$ genes were amplified using the primer pair TUB-F1/TUB-R1 and Qo13ext/Qo14ext with polymerase chain reaction (PCR) conditions previously described by Banno et al. (3), and Leroux et al. (25), respectively. To investigate the nucleotide alterations at amino acid positions 143 of Cytb and 198 of $\beta$-tubulin, amplicons were digested with the restriction enzyme Fnu4HI and ThaI (New England Biolabs, Beverly, MA), respectively, following the manufacturer's recommendations. PCR products were sequenced if the digestion did not reveal the expected fragments.

The complete bos 1 gene of $B$. cinerea isolates was amplified with five primer pairs, namely BF1/BR1, BF2/BR2, BF3/BR3, BF4/ $\mathrm{BR} 4$, and BF5/BR5 (28). PCR conditions were as previously described by Grabke et al. (17). The partial 3-keto reductase gene (erg27) was amplified and sequenced with primer pair F412_F and F412_R (18). The entire gene was amplified with primer pair erg27Beg and erg27End if sequence analysis of the fragment amplified with primers F412_F and F412_R did not show amino acid alterations at position 412 . Sequencing was conducted with primers erg27Beg, erg27End, erg1800down, and erg2000up (15). The iron-sulfur protein $(\mathrm{SdhB})$, target gene of SDHI fungicides, was amplified using the primer pair IpBcBeg/IpBcEnd 2 as described previously (25). The mrrl gene was amplified in two parts; the upstream region was amplified with primers mrr1_atg/TF1-2_new and the downstream region was amplified with TF1-3_new/TF1-4 (19). The $m f s M 2$ promoter region of $B$. cinerea was amplified with primers Prom_Mfs2_1fw/Prom_Mfs2_2rev (31).

Fragments were separated on a 1 and $2 \%$ (for digested PCR products) agarose gel, stained with ethidium bromide, and visualized under UV-light. For sequencing, the PCR products were purified using the ExoSAP-IT PCR purification kit (USB Corporation, Cleveland, $\mathrm{OH}$ ) following manufacturer's instructions and sequenced at the Clemson University Genomics Institute, Clemson, SC. Nucleotide sequences were analyzed and aligned with DNASTAR sequence analysis software (DNASTAR, Inc., Madison, WI).

RNA extraction and expression analyses. AtrB expression analysis was conducted in a sensitive isolate and isolates with the MDR1 and MDR1h phenotypes. A total of $2 \mathrm{ml}$ of potato dextrose broth $(\mathrm{PDB})$ in polystyrene petri dishes $(60 \times 15 \mathrm{~mm})$ was inoculated with $5 \times 10^{6}$ conidia and incubated on a rotary shaker for $14.5 \mathrm{~h}$ at room temperature and $150 \mathrm{rpm}$. After $14.5 \mathrm{~h}$ the germlings were incubated for another 30 min either with or without fludioxonil formulated as Scholar SC fungicide at a final concentration of $1 \mu \mathrm{g} / \mathrm{ml}$. For RNA isolation, the liquid culture was transferred into a $2-\mathrm{ml}$ tube and centrifuged for $4 \mathrm{~min}$ at 10,000 rpm. The pellet was washed

TABLE 1. Name, origin, year of isolation, and host of Botrytis cinerea isolates used in this study

\begin{tabular}{llcc}
\hline Isolate name & \multicolumn{1}{c}{ Origin } & Year of isolation & Host \\
\hline D09_K_A31z & Germany & 2009 & Strawberry \\
WIC2 $^{\text {z }}$ & Monetta, SC & 2011 & Strawberry \\
FLOR5 & Florence, SC & 2011 & Strawberry \\
HP9 & High Point, NC & 2011 & Strawberry \\
NC4 & Duplin, NC & 2011 & Strawberry \\
HRY1 & Chesapeake, VA & 2013 & Strawberry \\
JEY2013.1 & Chesnee, SC & 2013 & Strawberry \\
JEY2013.2 & Chesnee, SC & 2013 & Strawberry \\
JLEY2 & Chesnee, SC & 2013 & Strawberry \\
CT1 & Somers, CT & 2013 & Strawberry \\
CT3 & Somers, CT & 2013 & Strawberry \\
UGA1 & Berrien County, GA & 2013 & Blackberry \\
\hline
\end{tabular}

${ }^{\mathrm{z}} B$. cinerea isolates used only in reverse transcription-polymerase chain reaction assays. 
twice with ice-cold water followed by centrifugation. Total fungal RNA was extracted using the MasterPure Yeast RNA Purification Kit (Epicentre, Madison, WI) according to the manufacturer's instructions. RNA concentration and purity was determined using spectrophotometric analysis with a NanoDrop 2000 Spectrophotometer (Thermo Scientific, Waltham, MA). One microgram of RNA was reverse-transcribed into cDNA with the iScript cDNA Synthesis Kit (Bio-Rad Laboratories Inc., Hercules, CA) according to the manufacturer's instructions. Quantitative reverse transcription-PCR (RT-PCR) was performed in an iCycler Thermal Cycler with an iQ Multicolor Real-Time PCR Detection System (Bio-Rad Laboratories) as described previously (17) with the exception that primers atrBfor/atrBrev were used for $a t r B$ expression analysis following published amplification protocols (19). Expression of the gene was calculated according to Pfaffel (39). Transcript levels were normalized against the expression levels of housekeeping genes encoding elongation factor $1 \alpha$ and shown as normalized fold-expression levels relative to noninduced germlings of a sensitive isolate. Means of at least two biological replicates are shown. Three technical replicates of PCR reaction were used for each biological replicate.

Fitness studies. The following fitness components were investigated for isolates sensitive (FLOR5, HP9, NC4) and resistant (HRY1, JEY2013.1, JEY2013.2, JLEY2, CT1, CT3, and UGA1) to seven classes of fungicides. Three replicate dishes per isolate were used and all experiments were performed twice.

Mycelial growth and sclerotia production. Mycelial growth was measured at three different temperatures $\left(11,22\right.$, and $\left.30^{\circ} \mathrm{C}\right)$ on 9-cm-diameter petri dishes containing $10 \mathrm{ml}$ of minimal medium (MM: $\mathrm{KH}_{2} \mathrm{PO}_{4}$ at $1 \mathrm{~g} / \mathrm{liter}, \mathrm{MgSO}_{4}$ at $0.5 \mathrm{~g} /$ liter, $\mathrm{KCl}$ at $0.5 \mathrm{~g} / \mathrm{liter}$, $\mathrm{FeSO}_{4} \cdot 7 \mathrm{H}_{2} \mathrm{O}$ at $1 \mathrm{mg} / \mathrm{liter}$, glucose at $20 \mathrm{~g} / \mathrm{liter}, \mathrm{NaNO}_{3}$ at $2 \mathrm{~g} / \mathrm{liter}$, and agar at $12.5 \mathrm{~g} /$ liter), an intermediate medium (IM: $\mathrm{MgSO}_{4}$ at $2 \mathrm{~g} /$ liter, glucose at $4 \mathrm{~g} / \mathrm{liter}$, peptone at $4 \mathrm{~g} / \mathrm{liter}, 0.02 \%$ Tween, $\mathrm{KH}_{2} \mathrm{PO}_{4}$ at $0.75 \mathrm{~g} / \mathrm{liter}$, citric acid at $2 \mathrm{~g} / \mathrm{liter}$, and agar at 12.5 $\mathrm{g} /$ liter), or a rich medium ( $\mathrm{RM}: \mathrm{CaCO}_{3}$ at $3 \mathrm{~g} /$ liter, $\mathrm{KCl}$ at $28 \mathrm{~g} / \mathrm{liter}$, V8 at $200 \mathrm{ml} /$ liter [Campbell Food, Belgium], and agar at 12.5 $\mathrm{g} /$ liter). The IM medium was reported previously to mimic plant substrates (30). Petri dishes were inoculated with a medium plug ( $5 \mathrm{~mm}$ in diameter) containing nonsporulating mycelium from a 5-day-old culture grown on YSS medium (yeast extract at $2 \mathrm{~g} / \mathrm{liter}$, glucose at $10 \mathrm{~g} /$ liter, $\mathrm{KH}_{2} \mathrm{PO}_{4}$ at $2 \mathrm{~g} /$ liter, $\mathrm{K}_{2} \mathrm{HPO}_{4}$ at $1.5 \mathrm{~g} /$ liter, $\left(\mathrm{NH}_{4}\right)_{2} \mathrm{SO}_{4}$ at $1 \mathrm{~g} / \mathrm{liter}, \mathrm{MgSO}_{4} \cdot 7 \mathrm{H}_{2} \mathrm{O}$ at $0.5 \mathrm{~g} /$ liter, and agar at $12.5 \mathrm{~g} /$ liter). Colony diameters were measured after 4 days of incubation in the dark. After that, each plate was kept in the dark for 3 weeks and 3 days for the production of sclerotia (5).
Spore production in vitro. To assess the ability to produce spores, malt yeast agar (MY) plates were inoculated with a 5-mm-diameter mycelial plug taken from a 5-day-old culture grown on YSS medium and incubated for 10 days at 11,22 , and $30^{\circ} \mathrm{C}$ under continuous white light. Sporulating colonies were rinsed with $15 \mathrm{ml}$ of distilled sterile water and the conidial suspension was filtered through $34 \mu \mathrm{m}$ nylon mesh to remove fungal mycelium. The spore concentration in the suspension was estimated using a hemacytometer (5).

Osmotic sensitivity. Osmotic sensitivity was assessed by determining radial growth of isolates on PDA amended with $4 \%$ of sodium chloride $(\mathrm{NaCl})$. A 5-mm-diameter mycelial plug taken from 5-day-old culture grown on YSS was transferred to the center of the amended and nonamended medium. Colony diameter was measured after 3 days of incubation at $22^{\circ} \mathrm{C}$ in the dark. The percentage of mycelial growth inhibition was calculated as previously described (12).

Data analysis. A statistical model related the experimental responses of the fitness test to replication, isolate, fungicide treatment, and their combination. The method of least squares was used to estimate the model terms connected with the factors. The data of the two independent experiments for each experimental response were combined and significant differences were determined through Tukey's honest significant difference test. All calculations were performed by IBM SPSS Statistics, version 19 (IBM SPSS, Armonk, NY), and all tests were performed with $\alpha=0.05$ except where described otherwise.

\section{RESULTS}

Sensitivity of isolates to boscalid, cyprodinil, fenhexamid, fludioxonil, iprodione, pyraclostrobin, and thiophanate-methyl. The multifungicide resistance phenotypes of the isolates HRY1, JEY2013.1, JEY2013.2, JLEY2, CT1, CT3, and UGA1 determined by mycelial inhibition studies as part of our region-wide monitoring program were confirmed with a spore germination assay published previously (44). All isolates were highly resistant to cyprodinil, fenhexamid, pyraclostrobin, and thiophanate-methyl and resistant to boscalid (Table 2). Two isolates (JEY2013.1 and JEY2013.2) were low resistant and the remaining ones (HRY1, JLEY2, CT1, CT3, and UGA1) were moderately resistant to iprodione. Isolates HRY1, JEY2013.1, JEY2013.2, and JLEY2 were low resistant to fludioxonil with $\mathrm{EC}_{50}$ values ranging from 0.33 to $0.40 \mu \mathrm{g} / \mathrm{ml}$; isolates CT1, CT3, and UGA1 were moderately resistant to fludioxonil with $\mathrm{EC}_{50}$ values ranging from 1.7 to $3.1 \mu \mathrm{g} / \mathrm{ml}$

TABLE 2. Sensitivity phenotype, presence or absence of associated point mutations in the class III histidine kinase (bos 1 ), $\beta$-tubulin, cytochrome b (cytb), partial 3-keto reductase gene (erg27), and the succinate dehydrogenase iron-sulfur protein ( $s d h B)$ genes; and MDR phenotype and effective inhibitory concentrations $\left(\mathrm{EC}_{50}\right.$ values) for fludioxonil of Botrytis cinerea isolates ${ }^{\mathrm{v}}$

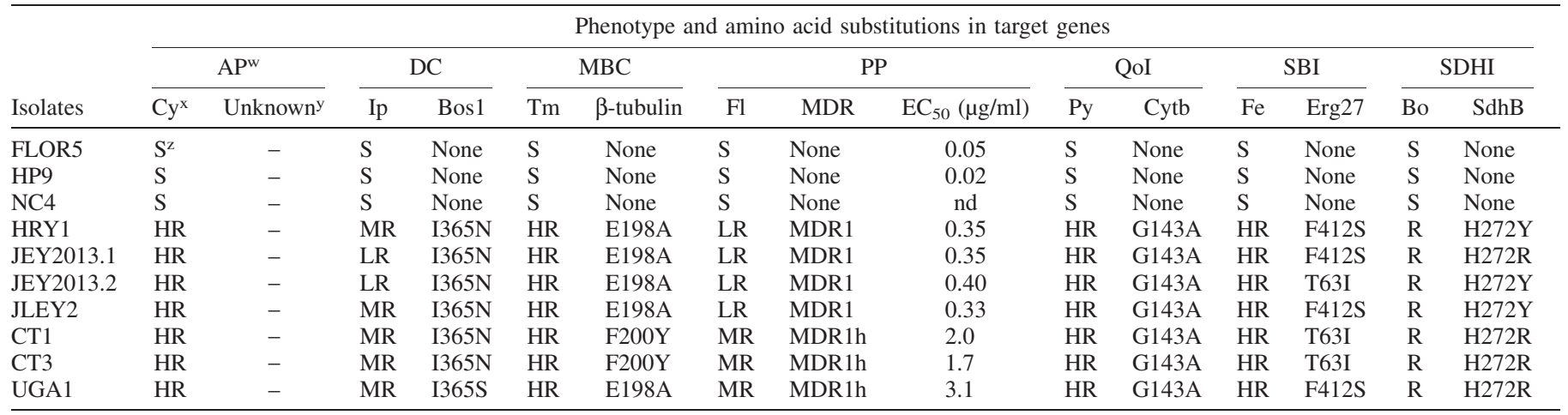

${ }^{\mathrm{v}}$ For fungicide sensitivity a conidia germination assay was performed as previously described by Weber and Hahn (44).

w Fungicide group name: anilinopyrimidines (AP); dicarboximides (DC); methyl benzimidazole carbamates (MBC); phenylpyrroles (PP); quinone outside inhibitors (QoI); SBI class III (SBI); and succinate dehydrogenase inhibitors (SDHI).

${ }^{x}$ Cy, cyprodinil; Ip, iprodione; Tm, thiophanate-methyl; Fl, fludioxonil; Py, pyraclostrobin; Fe, fenhexamid; and Bo, boscalid.

$\mathrm{y}-$ and nd indicate not determined.

${ }^{\mathrm{z}} \mathrm{S}$, sensitive; LR, low resistant; MR, moderately resistant; R, resistant; and HR, highly resistant. 
(Table 2). The groups of isolates with low and high $\mathrm{EC}_{50}$ values for fludioxonil were categorized as MDR1 and MDR1h phenotypes (Table 2), respectively, based on a spore germination assay previously described by Leroch et al. (23). All of these seven isolates failed to germinate on cycloheximide $(50 \mu \mathrm{g} / \mathrm{ml})$ but germinated on tolnaftate $(5 \mu \mathrm{g} / \mathrm{ml})$, cyprodinil $(0.03 \mu \mathrm{g} / \mathrm{ml})$, and fludioxonil $(0.2 \mu \mathrm{g} / \mathrm{ml})$. In addition, MDR $1 \mathrm{~h}$ isolates were able to germinate on fludioxonil at $1 \mu \mathrm{g} / \mathrm{ml}$ (data not shown). B. cinerea isolates FLOR5, $\mathrm{HP} 9$, and NC4 were characterized as sensitive to all fungicides in previous studies $(11,12,14,17,18)$.

Mutations in target genes. To determine whether resistance was based on single gene resistance, the presence or absence of mutations in genes encoding target proteins for iprodione, thiophanate-methyl, pyraclostrobin, fenhexamid, and boscalid was investigated for three isolates that were sensitive and seven that were resistant to seven classes of fungicides. The bosl gene from all iprodione sensitive and resistant isolates was sequenced in its entirety with five primer pairs (28). With only one exception, all low resistant and moderately resistant isolates had a mutation at codon 365 (ATC to AAC), resulting in an amino acid change from isoleucine to asparagine (I365N). However, the moderately resistant blackberry isolate UGA1 had an amino acid change from isoleucine to serine at codon 365 (I365S; Table 2). For thiophanatemethyl resistance, a PCR product of approximately $380 \mathrm{bp}$ in size was amplified. The amplicon from five isolates highly resistant to thiophanate-methyl (HRY1, JEY2013.1, JEY2013.2, JLEY2, and UGA1) was successfully digested with ThaI, indicating the presence of the E198A mutation (Table 2). The PCR product from the sensitive isolates remained undigested (data not shown). The remaining highly resistant isolates (CT1 and CT3) were not digested with ThaI and therefore subjected to sequence analysis. The target gene revealed a nucleotide change from phenylalanine to tyrosine at amino acid position 200 (F200Y; Table 2). Primers Qo13ext and Qo14ext amplified a 560-bp fragment from $c y t b$ for all sensitive and highly resistant isolates to pyraclostrobin. Enzyme Fnu4HI cut all amplicons from resistant isolates into two fragments of 318 and $242 \mathrm{bp}$ in length indicating the presence of the G143A mutation (Table 2). The PCR product from the isolates sensitive to pyraclostrobin remained undigested (data not shown). The fenhexamid highly resistant isolates HRY1, JEY2013.1, JLEY2, and UGA1 yielded a band approximately 586 bp in size when DNA was amplified with primers F412_F and F412_R. Sequence analysis revealed that these isolates possessed the F412S mutation (Table 2). The fenhexamid-sensitive isolates FLOR5, HP9, and NC4 and the highly resistant ones CT1, CT3, and JEY2013.2 were screened for mutations in the $\operatorname{erg} 27$ gene. An amino acid change from threonine to isoleucine substitution at position 63 (T63I) was found in isolates highly resistant to fenhexamid but not in sensitive isolates (Table 2). Primers IpBcBeg and IpBcEnd 2 amplified PCR fragments of about $950 \mathrm{bp}$ in length from all isolates sensitive and resistant to boscalid. Sequencing analysis revealed nucleotide variations that corresponded with amino acid changes at position 272. Four of seven boscalid-resistant isolates (CT1, CT3, JEY2013.1, and UGA1) had the replacement of the histidine residue by arginine at position 272 (H272R). Replacement of histidine by a tyrosine residue (H272Y) was observed in the remaining resistant isolates (HRY1, JEY2013.2, and JLEY2). The SdhB subunit of all boscalid-sensitive isolates revealed no amino acid changes (Table 2). No other amino acid substitutions were detected. The target gene or genes for AP fungicide cyprodinil are still unknown.

Mutations in the transcription factor mrrl and the promoter sequences of $\boldsymbol{m} \boldsymbol{s} \boldsymbol{s} \boldsymbol{M} 2$. Previous studies have shown that certain mutations and a single deletion in the transcription factor $m r r l$ influence the $\operatorname{atr} B$ expression $(19,23,27)$. The nucleotide sequences of transcription factor $m r r l$ were compared between 14 isolates. Four mrrl sequences were available in GenBank, including sequences of three sensitive blackberry isolates (accession numbers KJ569562, KJ569563, and
KJ569564) and sensitive reference isolate T4 (accession number FQ790263.1). The sequences of all other isolates including nine strawberry isolates and blackberry isolate UGA1 representing fludioxonil-sensitive, -low resistance, and -moderate resistance phenotypes were determined in this study. Fifteen different mutations were unique to the four MDR1 isolates compared with the pool of sensitive isolates and seven of them were unique to both MDR1 and MDR1h isolates of this study. Mutations T296A, D354Y, G620R, and G702N were linked previously to MDR1 (19,27; Fig. 1). Mutations unique to our MDR1h isolates included a 3-bp deletion at amino acid position 497 in the $m r r l$ sequences. The deletion at position $497(\Delta \mathrm{L} / \mathrm{V} 497)$ has been previously associated with the MDR1h phenotypes ( $\Delta$ L497; 23; Fig. 1). Some mutations were found only in some MDR1h isolates. Isolate CT3 revealed mutation $\mathrm{N} 265 \mathrm{D}$ and isolate $\mathrm{CT} 1$ had mutation M701T (Table 3). Isolate CT3 also contained an amino acid substitution that was previously associated with MDR1, a change from alanine to threonine at position 296 (T296A; 19). With the exception of the sensitive isolates from strawberry and the MDR1 isolate JEY2013.2, isolates had two insertions of 18 and 21 bp in length in the $m r r l$ coding region that distinguishes Botrytis group $\mathrm{S}$ from $B$. cinerea isolates (23). No point mutations or insertions were detected in the $m f s M 2$ promoter region of isolates low resistant or moderately resistant to fludioxonil, indicating the absence of MDR2 phenotypes.

Expression of multidrug transporter gene atrB in sensitive, MDR1, and MDR1h isolates. As shown in Figure 2A and B, atrB transcript levels of MDR1 and MDR1h isolates were increased compared with non-MDR, fludioxonilsensitive isolate WIC2. The $\operatorname{atr} B$ expression levels of MDR1 isolates HRY1, JEY2013.1, JEY2013.2, and JLEY2 cultured on nonamended medium were increased 87- to 124-fold compared with the sensitive isolate (Fig. 2A). MRD1h reference isolate D09_KA31 revealed 220-fold higher expression levels compared with the sensitive isolate. In a separate, replicated study the $a t r B$ expression levels of MDR1h isolates CT1, CT3, and UGA1 cultured on unamended medium were 182- to 266-fold higher compared with the sensitive isolate (Fig. 2B). Fludioxonil exposure prior to RNA extraction increased expression of most isolates regardless of their phenotype.

Fitness studies. Several biological parameters (including mycelial growth, salt tolerance, and production of sclerotia and conidia) were investigated at various temperatures $\left(11,22\right.$, and $\left.30^{\circ} \mathrm{C}\right)$ using different nutritional conditions (MM, IM, RM, PDA $+4 \%$ $\mathrm{NaCl}$, and $\mathrm{MY}$ ) for three sensitive, four MDR1, and three MDR1h isolates. Mycelial growth rates were variable among and between sensitive and resistant isolates across all temperatures. Variations were most pronounced in IM medium at 11 and $22^{\circ} \mathrm{C}$. However, mycelia growth rates between sensitive and resistant isolates did not indicate significant differences. The same was true for mycelium of sensitive and MDR1 isolates grown on $\mathrm{NaCl}$-amended medium. However, MDR1h isolates were significantly more susceptible to salt stress compared with sensitive isolates (Table 4). Similar to the mycelial growth, sclerotia formation was variable among and between sensitive and resistant isolates. Interestingly, sclerotia formation at low temperature on MM medium was significantly greater in MDR1h isolates compared with sensitive and MDR1 isolates. On IM medium, with only one exception, MDR1 and MDR1h isolates produced significantly more sclerotia compared with sensitive isolates. At the higher temperature of $22^{\circ} \mathrm{C}$, this effect was not observed (Table 5). Spore production was not different between the three fungicide resistance phenotypes. No sclerotia or spores were produced at $30^{\circ} \mathrm{C}$ (data not shown).

\section{DISCUSSION}

The discovery of $B$. cinerea isolates resistant to all registered sitespecific fungicides for gray mold control (23; this manuscript) 
represents an unprecedented milestone of resistance development in plant pathogenic fungi. It signals that for this pathogen, sitespecific and reduced-risk fungicides may eventually become useless for integrated pest management if these genotypes became dominant in field populations. Resistance in single isolates to multiple fungicides is an emerging trend and was reported for many pathogens, including Alternaria alternata (2), Monilinia fructicola (8), Penicillium digitatum (41), Podosphaera fusca (38), Sclerotinia homeocarpa (34), and Venturia inaequalis (7). But none of these pathogens appears to be as adaptable to environmental stresses, including fungicide pressure, as $B$. cinerea. While alarming, the emergence of such multifungicide resistant "superstrains" should be used as an opportunity to identify potential weaknesses in current resistance management strategies.

Multifungicide resistance in B. cinerea is a well-known and welldescribed phenomenon. Isolates from commercial fields can accumulate resistance to four and five FRAC codes conferred by an accumulation of single resistances (SR) or resistance traits in individual isolates $(23,26)$. In the southeastern United States, the presence of $B$. cinerea populations with resistance to three and four chemical classes of fungicides is common and a low percentage (about 1.4\%) of isolates collected from seven southeastern U.S. states was even resistant to five and six chemical classes (13). The most difficult chemical class for $B$. cinerea and many other

A Kretschmer et al., 2009; Leroch et al., 2013

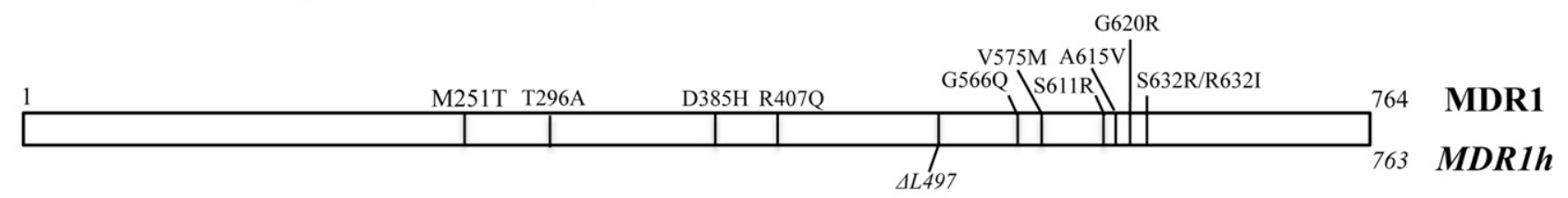

B Li et al., 2014

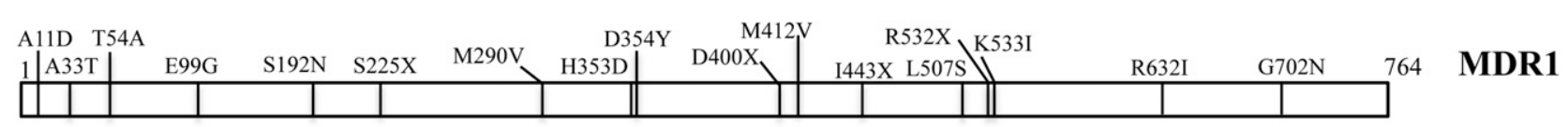

\section{Present study}

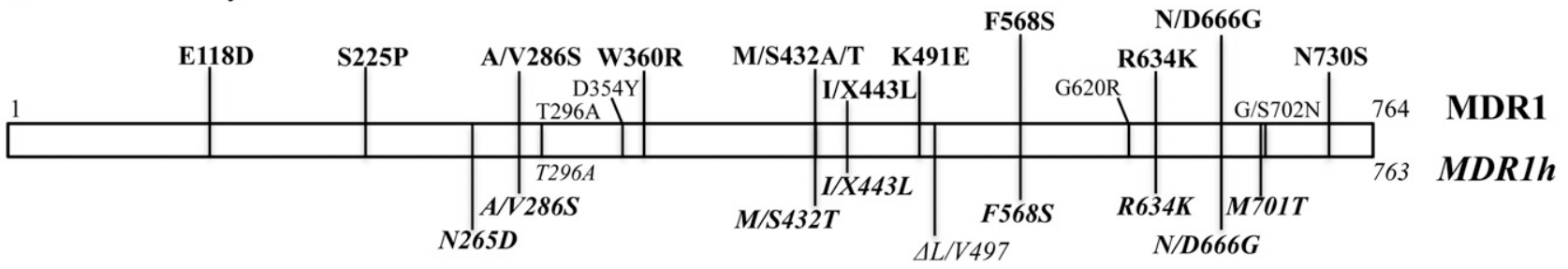

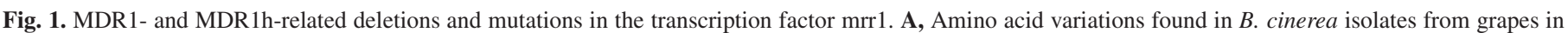

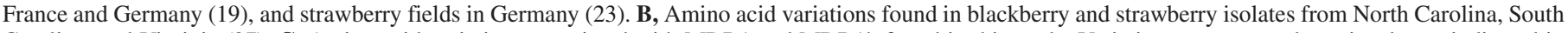

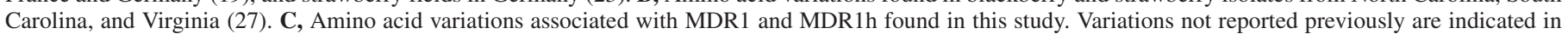
bold. Amino acid deletion at position 497 is indicated with a " $\Delta$ ". Deletions or amino acid variations unique to our MDR1h phenotypes are displayed in italics.

TABLE 3. Amino acid substitutions in transcription factor mrrl gene sequences of Botrytis cinerea isolates displaying MDR1 and MDR1h phenotypes

\begin{tabular}{|c|c|c|c|c|c|c|c|c|c|c|c|c|c|c|}
\hline \multirow[b]{3}{*}{ Amino acid position } & \multicolumn{14}{|c|}{ Isolates } \\
\hline & \multicolumn{7}{|c|}{ Sensitive } & \multicolumn{4}{|c|}{ MDR1 } & \multicolumn{3}{|c|}{ MDR1h } \\
\hline & $\mathrm{T} 4$ & FLOR5 & HP9 & $\mathrm{NC} 4$ & $\mathrm{CB} 3 \mathrm{a}$ & $\mathrm{KC} 20$ & $\mathrm{MC} 14$ & HRY1 & JEY 2013.1 & JEY 2013.2 & JLEY2 & CT1 & CT3 & UGA1 \\
\hline 118 & $\mathrm{E}$ & $\mathrm{E}$ & $\mathrm{E}$ & $\mathrm{E}$ & $\mathrm{E}$ & $\mathrm{E}$ & $\mathrm{E}$ & $\mathrm{E}$ & $\mathrm{D}$ & $\mathrm{E}$ & $\mathrm{E}$ & $\mathrm{E}$ & $\mathrm{E}$ & $\mathrm{E}$ \\
\hline 225 & $\mathrm{~S}$ & $\mathrm{~S}$ & $\mathrm{~S}$ & $\mathrm{~S}$ & $\mathrm{~S}$ & $\mathrm{~S}$ & $\mathrm{~S}$ & $\mathrm{~S}$ & $\mathrm{P}$ & $\mathrm{S}$ & $\mathrm{S}$ & $\mathrm{S}$ & $\mathrm{S}$ & $\mathrm{S}$ \\
\hline 265 & $\mathrm{~N}$ & $\mathrm{~N}$ & $\mathrm{~N}$ & $\mathrm{~N}$ & $\mathrm{~N}$ & $\mathrm{~N}$ & $\mathrm{~N}$ & $\mathrm{~N}$ & $\mathrm{~N}$ & $\mathrm{~N}$ & $\mathrm{~N}$ & $\mathrm{~N}$ & $\mathrm{D}$ & $\mathrm{N}$ \\
\hline 286 & $\mathrm{~V}$ & V & V & V & A & V & $\mathrm{V}$ & $\mathrm{S}$ & A & V & $\mathrm{S}$ & $\mathrm{S}$ & $\mathrm{S}$ & $\mathrm{S}$ \\
\hline 296 & $\mathrm{~T}$ & $\mathrm{~T}$ & $\mathrm{~T}$ & $\mathrm{~T}$ & $\mathrm{~T}$ & $\mathrm{~T}$ & $\mathrm{~T}$ & A & $\mathrm{T}$ & $\mathrm{T}$ & A & $\mathrm{T}$ & A & $\mathrm{T}$ \\
\hline 354 & $\mathrm{D}$ & $\mathrm{D}$ & $\mathrm{D}$ & $\mathrm{D}$ & D & D & D & D & $\mathrm{D}$ & $\mathrm{Y}$ & $\mathrm{D}$ & D & D & D \\
\hline 360 & W & W & W & W & W & W & W & W & W & $\mathrm{R}$ & W & W & W & W \\
\hline 432 & $\mathrm{M}$ & M & M & M & $\mathrm{S}$ & M & M & $\mathrm{T}$ & $\mathrm{S}$ & M & A & $\mathrm{T}$ & $\mathrm{T}$ & $\mathrm{T}$ \\
\hline 443 & I & I & I & I & $X$ & I & I & $\mathrm{L}$ & $\mathrm{L}$ & I & $\mathrm{L}$ & $\mathrm{L}$ & $\mathrm{L}$ & $\mathrm{L}$ \\
\hline 491 & $\mathrm{~K}$ & $\mathrm{~K}$ & $\mathrm{~K}$ & $\mathrm{~K}$ & $\mathrm{~K}$ & $\mathrm{~K}$ & K & $\mathrm{K}$ & $\mathrm{K}$ & $\mathrm{E}$ & K & $\mathrm{K}$ & $\mathrm{K}$ & $\mathrm{K}$ \\
\hline 497 & $\mathrm{~L}$ & $\mathrm{~L}$ & $\mathrm{~L}$ & $\mathrm{~L}$ & $\mathrm{~V}$ & $\mathrm{~L}$ & $\mathrm{~L}$ & V & $\mathrm{V}$ & $\mathrm{L}$ & $\mathrm{V}$ & $\Delta^{\mathrm{z}}$ & $\Delta$ & $\Delta$ \\
\hline 568 & $\mathrm{~F}$ & $\mathrm{~F}$ & $\mathrm{~F}$ & $\mathrm{~F}$ & $\mathrm{~F}$ & $\mathrm{~F}$ & $\mathrm{~F}$ & $\mathrm{~S}$ & $\mathrm{~F}$ & $\mathrm{~F}$ & $\mathrm{~S}$ & $\mathrm{~S}$ & $\mathrm{~S}$ & $\mathrm{~S}$ \\
\hline 620 & $\mathrm{G}$ & $\mathrm{G}$ & $\mathrm{G}$ & $\mathrm{G}$ & $\mathrm{G}$ & $\mathrm{G}$ & $\mathrm{G}$ & $\mathrm{G}$ & $\mathrm{R}$ & $\mathrm{G}$ & $\mathrm{G}$ & $\mathrm{G}$ & $\mathrm{G}$ & $\mathrm{G}$ \\
\hline 634 & $\mathrm{R}$ & $\mathrm{R}$ & $\mathrm{R}$ & $\mathrm{R}$ & $\mathrm{R}$ & $\mathrm{R}$ & $\mathrm{R}$ & $\mathrm{K}$ & $\mathrm{R}$ & $\mathrm{R}$ & K & $\mathrm{K}$ & $\mathrm{K}$ & $\mathrm{K}$ \\
\hline 666 & $\mathrm{~N}$ & $\mathrm{~N}$ & $\mathrm{~N}$ & $\mathrm{~N}$ & D & $\mathrm{N}$ & $\mathrm{N}$ & $\mathrm{G}$ & D & $\mathrm{N}$ & $\mathrm{G}$ & $\mathrm{G}$ & $\mathrm{G}$ & $\mathrm{G}$ \\
\hline 701 & $\mathrm{M}$ & M & M & M & M & M & M & M & M & M & M & $\mathrm{T}$ & M & M \\
\hline 702 & $\mathrm{G}$ & $\mathrm{G}$ & $\mathrm{G}$ & $\mathrm{G}$ & $\mathrm{S}$ & $\mathrm{G}$ & $\mathrm{G}$ & $\mathrm{S}$ & $\mathrm{N}$ & $\mathrm{G}$ & $\mathrm{S}$ & $\mathrm{S}$ & $\mathrm{S}$ & $\mathrm{S}$ \\
\hline 730 & $\mathrm{~N}$ & $\mathrm{~N}$ & $\mathrm{~N}$ & $\mathrm{~N}$ & $\mathrm{~N}$ & $\mathrm{~N}$ & $\mathrm{~N}$ & $\mathrm{~N}$ & $\mathrm{~N}$ & $\mathrm{~S}$ & $\mathrm{~N}$ & $\mathrm{~N}$ & $\mathrm{~N}$ & $\mathrm{~N}$ \\
\hline
\end{tabular}

$\mathrm{z} \Delta$, deletion of leucine (L) or valine (V) at amino acid position 497. 


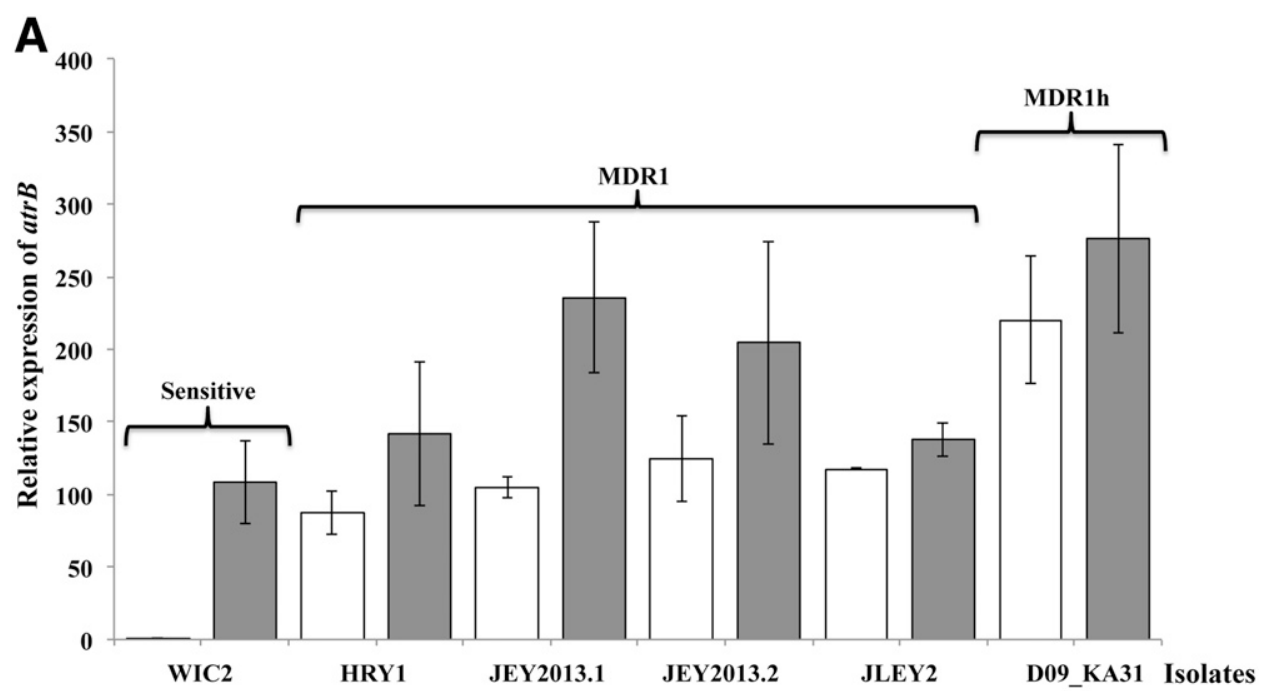

B

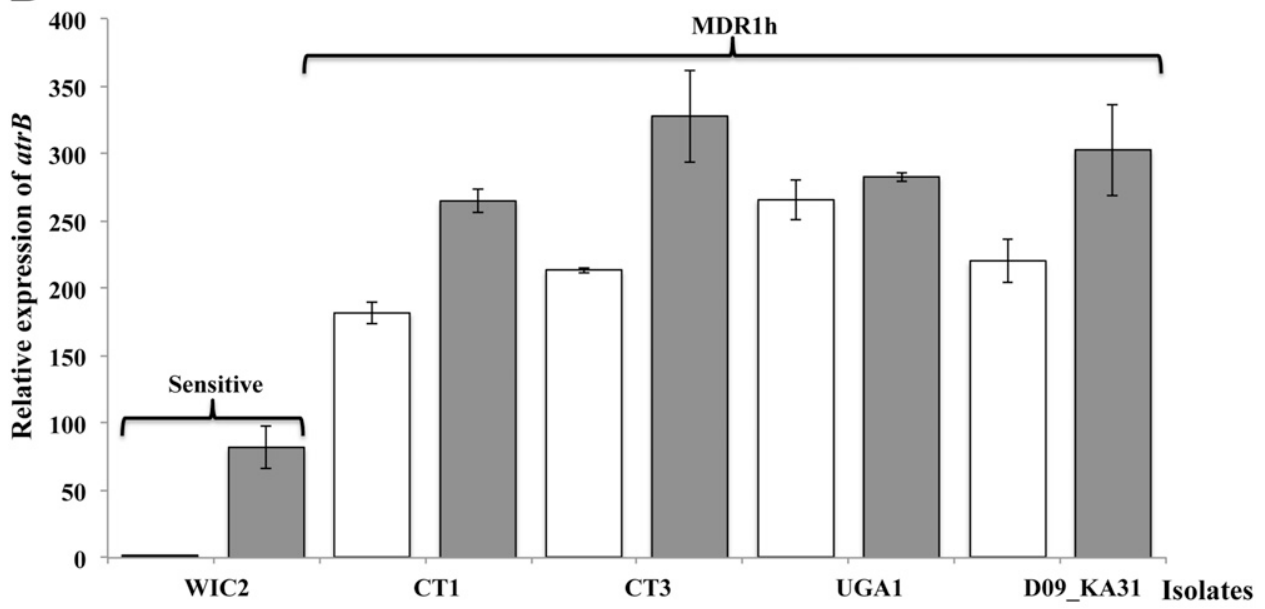

Fig. 2. A, Transcript levels of atrB in isolates sensitive to all fungicides (WIC2), resistant to seven classes of fungicides, and displaying MDR1 (HRY1, JEY2013.1, JEY2013.2, and JLEY2), and the reference MDR1h isolate D09_KA31 determined by quantitative reverse transcription-polymerase chain reaction (RT-PCR). B, Transcript levels of atrB in isolates sensitive to all fungicides (WIC2), resistant to seven classes of fungicides and displaying MDR1h (CT1, CT3, and UGA1), and the reference isolate D09_KA31. Values indicate expression levels relative to the expression levels of the lowest expressor (WIC2). White and gray bars indicate expression without and with fludioxonil exposure prior to RNA extraction, respectively. Mean values and standard deviations were calculated from two biological replicates.

TABLE 4. Comparison of mycelial growth and mycelial growth inhibition on potato dextrose agar amended with $4 \% \mathrm{NaCl}$ for Botrytis cinerea isolates sensitive or resistant to seven classes of fungicides

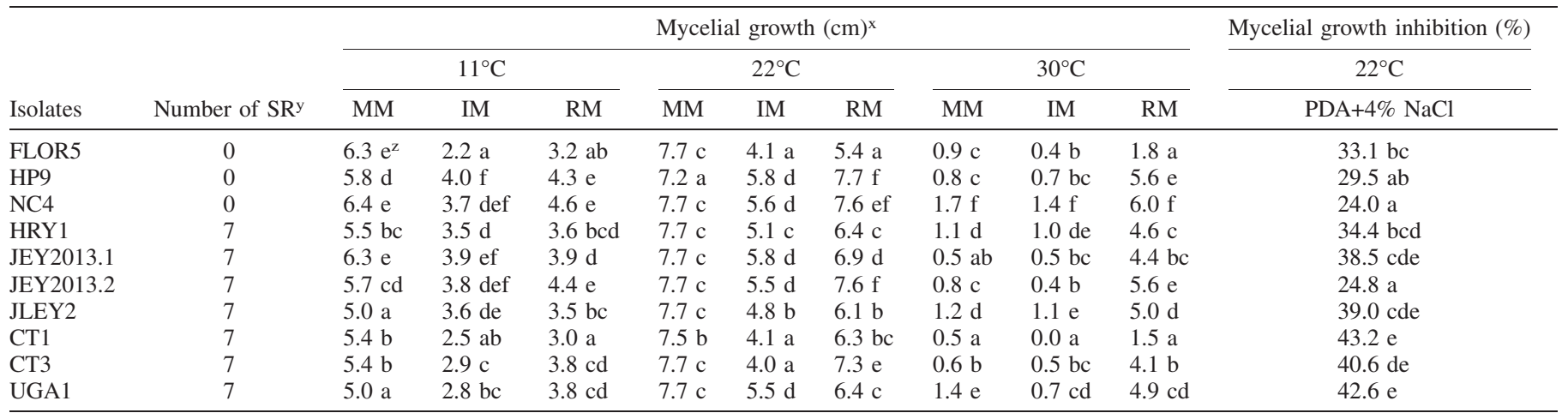

${ }^{x}$ Radial growth in $\mathrm{cm}$ measured in three different media (minimal medium [MM]; intermediate medium [IM]; and rich medium [RM]) at three different temperatures after 4 days of incubation.

${ }^{y}$ Number of single resistance (SR): 0 indicates isolates sensitive to seven classes of fungicides; 7 indicates isolates resistant to boscalid, cyprodinil, fenhexamid, fludioxonil, iprodione, pyraclostrobin, and thiophanate-methyl fungicides.

${ }^{z}$ Numbers in each column followed by the same letter are not significantly different at $\alpha=0.05$ as determined by analysis of variance. Mean separation was conducted using Tukey's honest significant difference test. 
pathogens to overcome appears to be FRAC code 12. In this study we show that resistances to FRAC 12 was based on MDR1 and MDR1h, two resistance phenotypes that were first discovered in European $B$. cinerea isolates. The MDR1 phenotype was found in field isolates from French vineyards (19), German strawberry fields (23), and one blackberry field in North Carolina (27). MDR1 is mediated by several point mutations in the transcription factor $m r r l$ leading to overexpression of ABC transporter gene atrB $(19,23,27)$. The MDR1 isolates analyzed in this study contained both new and previously described mutations, including T296A and G620R in mrrl also found in European isolates $(19,23)$. The MDR1h phenotype is associated with a 3-bp deletion at position 497 in the mrrl-exon and prior to this study was only reported in German strawberry isolates (23). The atrB expression levels for MDR1h isolates were higher compared with MDR1 isolates, which is consistent with observations from Germany (23).

Among the $10 \mathrm{~B}$. cinerea isolates analyzed in this study (three sensitive, four MDR1, and three MDR1h), six of them (three MDR1 and all MDR1h) contained the $B$. cinerea group $\mathrm{S}$ signature consisting of two insertions of 18 and 21 bp in $m r r 1$. Group S isolates were first described in isolates from strawberry fields in Germany (23) and later in B. cinerea isolates from blackberry in South Carolina and North Carolina (27). In German isolates the MDR1h phenotype was only discovered in isolates belonging to group $\mathrm{S}$, which in turn were only isolated from strawberries (23). Isolates from the United States with the MDR1h phenotype were from strawberry and blackberry, expanding the host range discovered for group $\mathrm{S}$ isolates to other small fruits.

The isolates resistant to seven classes of fungicides (seven single resistance; 7SR) identified in this study came from four different states and represented five different genotypes based on target gene mutation profiles. The mutations in target genes conferring resistance to FRAC 1, 2, 7, 11, and 17 were identical to the ones found recently $(3,11,13,17,18)$, but most isolates had unique compositions of mutations. For example, the isolate HRY1 collected from Virginia had the combination of mutations I365N, E198A, G143A, F412S, and H272Y in Bos1, $\beta$-tubulin, Cytb, Erg27, and $\mathrm{SdhB}$, respectively, while isolates from Connecticut had the combination I365N, F200Y, G143A, T63I, and H272R, respectively. This indicates that the 7SR phenotypes emerged independently from others in different geographic locations and invalidates the hypothesis that mutant haplotypes emerged in a nursery, for example, and subsequently spread across other southern states by means of planting stock distribution. In addition to the genetic variability in target genes, variability was also found in $m r r l$ between isolates. In fact, none of the $m r r l$ genes were identical among resistant isolates. Even $\mathrm{mrrl}$ sequences of isolates from the same farms (JEY2013.1 and JEY2013.2 from South Carolina; CT1 and CT3 from Connecticut) revealed nucleotide differences in $m r r l$ and in some of the target genes analyzed.

The 7SR isolates discovered and characterized in this study came from "high input" strawberry fields and received weekly applications of fungicides during production season using alternations and mixture of many different FRAC codes. Spray records indicate that all farms had stepped up the use of Switch 62.5WG (cyprodinil+ fludioxonil) over the past 2 years due to documented resistance problems to other FRAC codes at each location. Resistance monitoring data from previous years were available for most locations and indicate that 5SR and 6SR isolates were present in 2012 and 2013 (13). It is therefore likely that the 7SR isolates emerged from 6SR isolates as a direct result of selection pressure of Switch. Such stepwise accumulation of single resistances in $B$. cinerea was documented recently (26). The 7SR isolates are likely to become more prevalent if current strategies to rotate and tank mix as many different FRAC codes as possible over the same production season are maintained. That is because the alternation and mixture of FRAC codes will likely give 7SR isolates a selective advantage over isolates with fewer single resistances.

At least for $B$. cinerea, other approaches for resistance management must be developed and implemented to avoid selection of 7SR isolates. A common sense way to not select for resistance is to spray less. Efforts in this direction include a focus on bloom applications for gray mold control and the development of decision support systems to reduce fungicide input. In Florida, for example, the applications of two classes of fungicides only during peak bloom periods were shown to provide significant control of gray mold $(22,45)$. It was demonstrated that low-rate application of captan during the early season and fenhexamid during the second peak bloom period improved control of gray mold and maintained or even increased marketable yield (20). With respect to decision support systems, infection risk is calculated based on weather data $(6,48)$. One model $(6)$ was successfully tested in experimental fields in Florida and found effective for timing fungicide sprays and controlling gray mold disease with a reduced number of applications $(29,35,36)$. Other options to manage more effectively multifungicide resistance could be to restrict certain FRAC codes to one or two applications per season and/or to not use every FRAC code every year. The product Switch for example may, according to the U.S. label, legally be used five times at the low rate per season and up to two times in a row. According to spray records, the fields

TABLE 5. Comparisons of sclerotia and spore production for Botrytis cinerea isolates sensitive or resistant to seven classes of fungicides

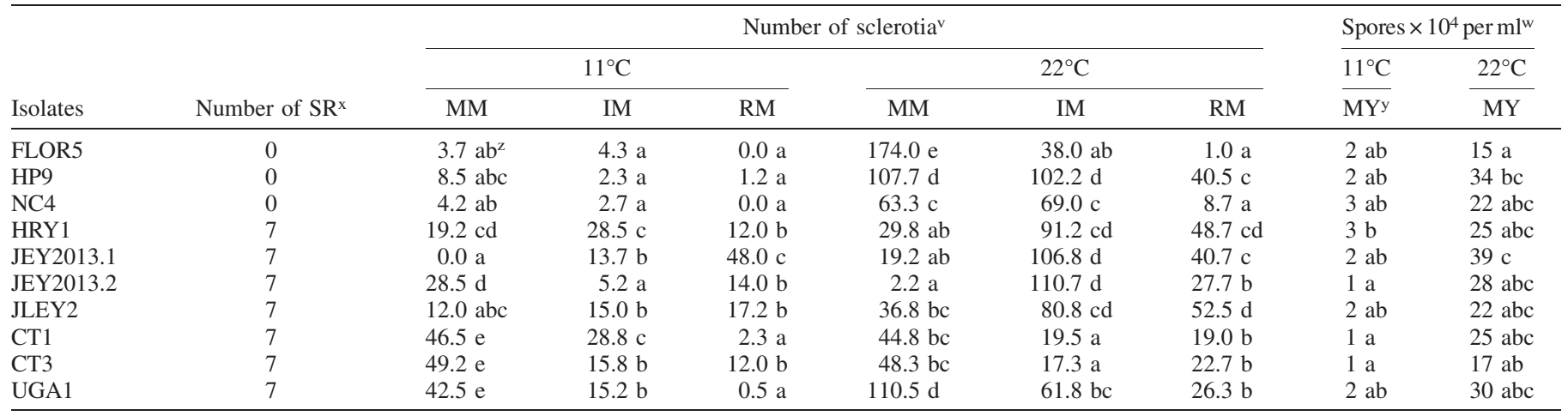

${ }^{v}$ Sclerotium production after 4 weeks on three different media (minimal medium [MM]; intermediate medium [IM]; and rich medium [RM]) at two different temperatures.

${ }^{w}$ Number of spores after 10 days of incubation at 11 and $22^{\circ} \mathrm{C}$.

${ }^{\mathrm{x}}$ Number of single resistance (SR): 0 indicates isolates sensitive to seven classes of fungicides; 7 indicates isolates resistant to boscalid, cyprodinil, fenhexamid, fludioxonil, iprodione, pyraclostrobin, and thiophanate-methyl fungicides.

y Malt yeast agar (MY).

${ }^{\mathrm{z}}$ Numbers in each column followed by the same letter are not significantly different at $\alpha=0.05$ as determined by analysis of variance. Mean separation was conducted using Tukey's honest significant difference test. 
from which our isolates derived received the legal maximum number of applications of Switch. In French vineyards, for example, it is recommended to alternate FRAC codes with a maximum of one spray per season for each chemical family (24). A combination of reduced number of applications and less frequent use of each FRAC code will likely help to increase the life span of FRAC codes.

Nonchemical means to reduce inoculum pressure may need to be implemented especially when fungicides are only applied as needed. Unfortunately, biopesticides have not been able to control gray mold in field trials (37). Less susceptible cultivars and protected culture can reduce gray mold disease under certain conditions $(21,47)$. Legard et al. (21) observed that under low disease pressure, cultivar Sweet Charlie was more susceptible than Carmine and Camarosa. Strawberry production in large plastic tunnels can also reduce gray mold disease. Compared with the open field, the epidemiology of this or other strawberry diseases in plastic tunnels are more predictable and less weather-dependent. In Florida, Xiao et al. (47) demonstrated a 90\% disease reduction under plastic tunnels when compared with open field-grown plants. However, the relatively high costs of protected culture systems are currently prohibitive for large-scale use in the United States (20). Also, the removal of senescent foliage and increased plant spacing can reduce gray mold incidence, but these cultural practices are relatively ineffective and expensive compared with use of fungicides $(21,32)$.

Whether any fitness cost associated with 7SR isolates matter in commercial production is debatable. Application of any sitespecific fungicide will give these isolates a very large competitive advantage. In our view, fitness cost would only become relevant if the producer stopped spraying altogether or if he just sprayed multisite fungicides such as thiram or captan. The fitness parameters addressed in this study did not reveal obvious fitness cost, however more tests including competitive fitness studies need to be done to assess potential fitness penalties. MDR1h isolates exhibited increased sensitivity to salt stress. A linkage of the fludioxonil-resistant phenotype and hypersensitivity to salt stress was also reported in laboratory mutants of Neurospora crassa and $B$. cinerea with dysfunctional genes involved in osmoregulation pathway $(16,49,50)$. In addition, increased sensitivity to salt stress was found in B. cinerea isolates from apple orchards in Washington State (51) and fludioxonil moderately resistant isolates from blackberry in North Carolina (27). However, MDR1h isolates produced more sclerotia at $11^{\circ} \mathrm{C}$ on $\mathrm{MM}$ compared with sensitive and MDR1 isolates and in general, MDR1 and MDR1h isolates produced significantly more sclerotia compared with sensitive isolates at the same temperature on IM medium. These results suggest that MDR1 and MDR1h isolates may cope better with low temperatures and limited nutritional conditions found in late autumn and winter. During the early spring, they may therefore produce more conidiophores and multinucleate conidia, increasing their dispersal and persistence during the strawberry season.

In this study we show that current antiresistance management strategies have not been able to prevent the independent development of resistance to all seven currently registered, sitespecific fungicides for gray mold control and document the presence of MDR1h in the North America.

\section{ACKNOWLEDGMENTS}

Technical contribution number 6127 of the Clemson University Experiment Station. This material is based on work supported by the CSREES/USDA, under project number SC-1000642. D. FernándezOrtuño received funding from the Marie Curie COFUND programme U-Mobility, co-financed by the University of Malaga, the European Commission FP7 under GA No. 246550, and Ministerio de Economía y Competitividad (COFUND2013-40259). We thank P. K. Bryson for technical support.

\section{LITERATURE CITED}

1. Amiri, A., Heath, S. M., and Peres, N. A. 2013. Phenotypic characterization of multifungicide resistance in Botrytis cinerea isolates from strawberry fields in Florida. Plant Dis. 97:393-401.

2. Avenot, H., Morgan, D. P., and Michailides, T. J. 2008. Resistance to pyraclostrobin, boscalid and multiple resistance to Pristine (R) (pyraclostrobin plus boscalid) fungicide in Alternaria alternata causing Alternaria late blight of pistachios in California. Plant Pathol. 57: 135-140.

3. Banno, S., Fukumori, F., Ichiishi, A., Okada, K., Uekusa, H., Kimura, M., and Fujimura, M. 2008. Genotyping of benzimidazole-resistant and dicarboximide-resistant mutations in Botrytis cinerea using real-time polymerase chain reaction assays. Phytopathology 98:397-404.

4. Beever, R. E., and Weeds, P. L. 2004. Taxonomy and genetic variation of Botrytis and Botryotinia. Pages 29-52 in: Botrytis: Biology, Pathology and Control. Y. Elad, B. Williamson, P. Tudzynski, and N. Delen, eds. Kluwer Academic Publishers, Dordrecht, The Netherlands.

5. Billard, A., Fillinger, S., Leroux, P., Lachaise, H., Beffa, R., and Debieu, D. 2012. Strong resistance to the fungicide fenhexamid entails a fitness cost in Botrytis cinerea, as shown by comparisons of isogenic strains. Pest Manag. Sci. 68:684-691.

6. Bulger, M. A., Ellis, M. A., and Madden, L. V. 1987. Influence of temperature and wetness duration on infection of strawberry flowers by Botrytis cinerea and disease incidence of fruit originating from infected flowers. Phytopathology 77:1225-1230.

7. Chapman, K. S., Sundin, G. W., and Beckerman, J. L. 2011. Identification of resistance to multiple fungicides in field populations of Venturia inaequalis. Plant Dis. 95:921-926.

8. Chen, F., Liu, X., and Schnabel, G. 2013. Field strains of Monilinia fructicola resistant to both MBC and DMI Fungicides isolated from stone fruit orchards in the eastern United States. Plant Dis. 97:1063-1068.

9. Chi, M. H., Park, S. Y., and Lee, Y. H. 2009. A quick and safe method for fungal DNA extraction. Plant Pathol. J. 25:108-111.

10. Choquer, M., Fournier, E., Kunz, C., Levis, C., Pradier, J. M., Simon, A., and Viaud, M. 2007. Botrytis cinerea virulence factors: New insights into a necrotrophic and polyphageous pathogen. FEMS Microbiol. Lett. 277: $1-10$

11. Fernández-Ortuño, D., Chen, F., and Schnabel, G. 2012. Resistance to pyraclostrobin and boscalid in Botrytis cinerea isolates from strawberry fields in the Carolinas. Plant Dis. 96:1198-1203.

12. Fernández-Ortuño, D., Chen, F., and Schnabel, G. 2013. Resistance to cyprodinil and lack of fludioxonil resistance in Botrytis cinerea isolates from strawberry in North and South Carolina. Plant Dis. 97:81-85.

13. Fernández-Ortuño, D., Grabke, A., Bryson, P. K., Amiri, A., Peres, N. A., and Schnabel, G. 2014. Fungicide resistance profiles in Botrytis cinerea from strawberry fields of seven southern U.S. states. Plant Dis. 98: 825-833.

14. Fernández-Ortuño, D., and Schnabel, G. 2012. First report of thiophanatemethyl resistance in Botrytis cinerea on strawberry from South Carolina. Plant Dis. 96:1700.

15. Fillinger, S., Leroux, P., Auclair, C., Barreau, C., Al Hajj, C., and Debieu, D. 2008. Genetic analysis of fenhexamid-resistant field isolates of the phytopathogenic fungus Botrytis cinerea. Antimicrobiol. Agents Chemother. 52:3933-3940.

16. Fujimura, M., Ochiai, N., Oshima, M., Motoyama, T., Ishiishi, A., Usami, R., Horikoshi, K., and Yamaguchi, I. 2003. Putative homologs of SSK22 MAPKK kinase and PBS2 MAPK kinase of Saccharomyces cerevisiae encoded by os- 4 and os- 5 genes for osmotic sensitivity and fungicide resistance in Neurospora crassa. Biosci. Biotechnol. Biochem. 67: 186-191.

17. Grabke, A., Fernández-Ortuño, D., Amiri, A., Li, X. P., Peres, N. A., Smith, P., and Schnabel, G. 2014. Characterization of iprodione resistance in Botrytis cinerea from strawberry and blackberry. Phytopathology 104: 396-402

18. Grabke, A., Fernández-Ortuño, D., and Schnabel, G. 2013. Fenhexamid resistance in Botrytis cinerea from strawberry fields in the Carolinas is associated with four target gene mutations. Plant Dis. 97:271-276.

19. Kretschmer, M., Leroch, M., Mosbach, A., Walker, A.-S., Fillinger, S., Mernke, D., Schoonbeek, H., Pradier, J.-M., Leroux, P., and De Waard, M. A. 2009. Fungicide-driven evolution and molecular basis of multidrug resistance in field populations of the grey mould fungus Botrytis cinerea. PLoS Pathog. 5:e1000696.

20. Legard, D. E., MacKenzie, S. J., Mertely, J. C., Chandler, C. K., and Peres, N. A. 2005. Development of a reduced use fungicide program for control of Botrytis fruit rot on annual winter strawberry. Plant Dis. 89:1353-1358.

21. Legard, D. E., Xiao, C. L., Mertely, J. C., and Chandler, C. K. 2000. Effects of plant spacing and cultivar on incidence of Botrytis fruit rot in annual strawberry. Plant Dis. 84:531-538. 
22. Legard, D. E., Xiao, C. L., Mertely, J. C., and Chandler, C. K. 2001. Management of Botrytis fruit rot in annual winter strawberry using captan, thiram, and iprodione. Plant Dis. 85:31-39.

23. Leroch, M., Plesken, C., Weber, R. W. S., Kauff, F., Scalliet, G., and Hahn, M. 2013. Gray mold populations in German strawberry fields show multiple fungicide resistance and are dominated by a novel clade close to Botrytis cinerea. Appl. Environ. Microbiol. 79:159-167.

24. Leroux, P. 2004. Chemical control of Botrytis and its resistance to chemical fungicides. Pages 195-222 in: Botrytis: Biology, Pathology and Control. Y. Elad, B. Williamson, P. Tudzynski, and N. Delen, eds. Kluwer Academic Publishers, Dordrecht, The Netherlands.

25. Leroux, P., Gredt, M., Leroch, M., and Walker, A.-S. 2010. Exploring mechanisms of resistance to respiratory inhibitors in field strains of Botrytis cinerea, the causal agent of gray mold. Appl. Environ. Microbiol. 76:6615-6630

26. Li, X. P., Fernández-Ortuño, D., Chen, S., Grabke, A., Luo, C. X., and Schnabel, G. 2014. Location-specific fungicide resistance profiles and evidence for stepwise accumulation of resistance in Botrytis cinerea. Plant Dis. 98:1066-1074.

27. Li, X. P., Fernández-Ortuño, D., Grabke, A., Bridges, W. C., and Schnabel, G. 2014. Resistance to fludioxonil in Botrytis cinerea isolates from blackberry and strawberry. Phytopathology 7:724-732.

28. Ma, Z., Yan, L., Luo, Y., and Michailides, T. J. 2007. Sequence variation in the two-component histidine kinase gene of Botrytis cinerea associated with resistance to dicarboximide fungicides. Pestic. Biochem. Physiol. 88: 300-306.

29. MacKenzie, S. J., and Peres, N. A. 2012. Use of leaf wetness and temperature to time fungicide applications to control Botrytis fruit rot of strawberry in Florida. Plant Dis. 96:529-536.

30. Manteau, S., Abouna, S., Lambert, B., and Legendre, L. 2003. Differential regulation by ambient $\mathrm{pH}$ of putative virulence factor secretion by the phytopathogenic fungus Botrytis cinerea. FEMS Microbiol. Ecol. 43:359-366.

31. Mernke, D., Dahm, S., Walker, A.-S., Laleve, A., Fillinger, S., Leroch, M., and Hahn, M. 2011. Two promoter rearrangements in a drug efflux transporter gene are responsible for the appearance and spread of multidrug resistance phenotype MDR2 in Botrytis cinerea isolates in French and German vineyards. Phytopathology 101:1176-1183.

32. Mertely, J. C., Chandler, C. K., Xiao, C. L., and Legard, D. E. 2000. Comparison of sanitation and fungicides for management of Botrytis fruit rot of strawberry. Plant Dis. 84:1197-1202.

33. Mertely, J. C., and Peres, N. A. 2009. Botrytis fruit rot or gray mold of strawberry. Page 230 in: Plant Pathology Department Series, Florida Cooperative Extension Service, Institute of Food and Agricultural (IFAS), Gainesville, FL.

34. Ok, C.-H., Popko, J. T., Campbell-Nelson, K., and Jung, G. 2011. In vitro assessment of Sclerotinia homoeocarpa resistance to fungicides and plant growth regulators. Plant Dis. 95:51-56.

35. Pavan, W., Fraisse, C. W., and Peres, N. A. 2011. Development of a webbased disease forecasting system for strawberries. Comput. Electron. Agric. 75:169-175.
36. Peres, N. A., and Amiri, A. 2013. Multi-year evaluation of standard- and model-timed fungicide applications for the control of Botrytis and anthracnose in commercial strawberry fields. http://www.apsnet.org/meetings/ Documents/2013_Meeting_Abstracts/aps2013abP314.htm

37. Peres, N. A., Mertely, J. C., Seijo, T. E., Torres, C., and Meister, C. W. 2006. Evaluation of biopesticides in conjunction with standard fungicides for control of Botrytis fruit rot in annual strawberry, 2004-05. Plant Dis. Manag. Rep. 61:SMF012.

38. Pérez-García, A., Romero, D., Fernández-Ortuño, D., López-Ruiz, F., De Vicente, A., and Torés, J. A. 2009. The powdery mildew fungus Podosphaera fusca (synonym Podosphaera xanthii), a constant threat to cucurbits. Mol. Plant Pathol. 10:153-160.

39. Pfaffl, M. W. 2001. A new mathematical model for relative quantification in real-time RT-PCR. Nucleic Acids Res. 29:45-50.

40. Rosewich, U. L., and Kistler, H. C. 2000. Role of horizontal gene transfer in the evolution of fungi. Annu. Rev. Phytopathol. 38:325-363.

41. Sánchez-Torres, P., and Tuset, J. J. 2011. Molecular insights into fungicide resistance in sensitive and resistant Penicillium digitatum strains infecting citrus. Postharvest Biol. Technol. 59:159-165.

42. Shirane, N., Masuko, M., and Hayashi, Y. 1988. Nuclear behaviour and division in germinating conidia of Botrytis cinerea. Phytopathology 78:1627-1630.

43. Stammer, G., and Speakman, J. 2006. Microtiter method to test the sensitivity of Botrytis cinerea to boscalid. J. Phytopathol. 154:508-510.

44. Weber, R. W. S., and Hahn, M. 2011. A rapid and simple method for determining fungicide resistance in Botrytis. J. Plant Dis. Prot. 118:17-25.

45. Wilcox, W. F., and Seem, R. C. 1994. Relationship between strawberry gray mold incidence, environmental variables, and fungicide applications during different periods of the fruiting season. Phytopathology 84: 264-270.

46. Williamson, B., Tudzynski, B., Tudzynski, P., and Van Kan, J. A. L. 2007. Botrytis cinerea: The cause of grey mould disease. Mol. Plant Pathol. 8: 561-580

47. Xiao, C. L., Chandler, C. K., Price, J. F., Duval, J. R., Mertely, J. C., and Legard, D. E. 2001. Comparison of epidemics of Botrytis fruit rot and powdery mildew of strawberry in large plastic tunnel and field production systems. Plant Dis. 85:901-909.

48. Xu, X. M., Harris, D. C., and Berrie, A. M. 2000. Modeling infection of strawberry flowers by Botrytis cinerea using field data. Phytopathology 90:1367-1374.

49. Yan, L., Yang, Q., Sundin, G. W., Li, H., and Ma, Z. 2010. The mitogenactivated protein kinase kinase BOS5 is involved in regulating vegetative differentiation and virulence in Botrytis cinerea. Fungal Genet. Biol. 47: 753-760

50. Yang, Q., Yan, L., Gu, Q., and Ma, Z. 2012. The mitogen-activated protein kinase $\mathrm{BcOs} 4$ is required for vegetative differentiation and pathogenicity in Botrytis cinerea. Appl. Environ. Microbiol. 96:481-492.

51. Zhao, H., Kim, Y. K., Huang, L., and Xiao, C. L. 2010. Resistance to thiabendazole and baseline sensitivity to fludioxonil and pyrimethanil in Botrytis cinerea populations from apple and pear in Washington State. Postharvest Biol. Technol. 56:12-18. 